\title{
Dietary supplementation of branched-chain amino acids increases muscle net amino acid fluxes through elevating their substrate availability and intramuscular catabolism in young pigs
}

\author{
Liufeng Zheng ${ }^{1}$, Fangrui Zuo ${ }^{1}$, Shengjun Zhao ${ }^{2}$, Pingli $\mathrm{He}^{3}$, Hongkui Wei ${ }^{1,4}$, Quanhang Xiang ${ }^{1}$, \\ Jiaman Pang ${ }^{1}$ and Jian Peng ${ }^{1,4 *}$ \\ ${ }^{1}$ Department of Animal Nutrition and Feed Science, College of Animal Science and Technology, Huazhong Agricultural \\ University, Wuban 430070, People's Republic of China \\ ${ }^{2}$ Department of Feed Science, Wuban Polytechnic University, Wuban 430070, People's Republic of China \\ ${ }^{3}$ State Key Laboratory of Animal Nutrition, College of Animal Science and Technology, China Agricultural University, \\ Beijing 100193, People's Republic of China \\ ${ }^{4}$ The Cooperative Innovation Center for Sustainable Pig Production, Wuban 430070, People's Republic of China \\ (Submitted 27 October 2016 - Final revision received 19 February 2017 - Accepted 4 March 2017 - First published online 27 April 2017)
}

\section{Abstract}

Branched-chain amino acids (BCAA) have been clearly demonstrated to have anabolic effects on muscle protein synthesis. However, little is known about their roles in the regulation of net AA fluxes across skeletal muscle in vivo. This study was aimed to investigate the effect and related mechanisms of dietary supplementation of BCAA on muscle net amino acid (AA) fluxes using the hindlimb flux model. In all fourteen 4 -week-old barrows were fed reduced-protein diets with or without supplemental BCAA for $28 \mathrm{~d}$. Pigs were implanted with carotid arterial, femoral arterial and venous catheters, and fed once hourly with intraarterial infusion of $p$-amino hippurate. Arterial and venous plasma and muscle samples were obtained for the measurement of AA, branched-chain $\alpha$-keto acids (BCKA) and 3-methylhistidine (3-MH). Metabolomes of venous plasma were determined by HPLC-quadrupole time-of-flight-MS. BCAA-supplemented group showed elevated muscle net fluxes of total essential AA, non-essential AA and AA. As for individual AA, muscle net fluxes of each BCAA and their metabolites (alanine, glutamate and glutamine), along with those of histidine, methionine and several functional non-essential AA (glycine, proline and serine), were increased by BCAA supplementation. The elevated muscle net AA fluxes were associated with the increase in arterial and intramuscular concentrations of BCAA and venous metabolites including BCKA and free fatty acids, and were also related to the decrease in the intramuscular concentration of 3-MH. Correlation analysis indicated that muscle net AA fluxes are highly and positively correlated with arterial BCAA concentrations and muscle net BCKA production. In conclusion, supplementing BCAA to reduced-protein diet increases the arterial concentrations and intramuscular catabolism of BCAA, both of which would contribute to an increase of muscle net AA fluxes in young pigs.

Key words: Branched-chain amino acids: Young pigs: Hindlimb muscle: Net amino acid fluxes: Metabolomic profiling

Enhancement of skeletal muscle protein deposition is of vital importance for livestock meat production ${ }^{(1)}$. Apart from being essential substrates for protein synthesis, branched-chain amino acids (BCAA; leucine (Leu), isoleucine (Ile) and valine (Val)), especially Leu, have been well demonstrated to be able to promote muscle anabolism by stimulating protein synthesis and inhibiting protein degradation ${ }^{(2-5)}$. Recently, we found that the mass of most muscles was increased in young pigs with supplementation of BCAA to reduced-protein diet ${ }^{(6)}$. However, the mechanisms underlying the anabolic effect of BCAA on muscle growth remain largely unknown.
Postnatal growth of skeletal muscle depends on the balance between protein synthesis and degradation. That is to say, to increase the muscle mass, protein synthesis should exceed protein degradation (resulting in protein deposition) ${ }^{(1)}$. Of note, the elevation of muscle protein synthesis does not always result in the increase of muscle mass ${ }^{(7,8)}$. Thus, only measuring protein synthesis may not be able to accurately and objectively present the mechanisms for the increase of muscle mass. As skeletal muscle primarily utilises amino acids (AA) for protein deposition, the increase of muscle net AA flux (calculated by arteriovenous difference technique) may contribute to the

Abbreviations: 3-MH, 3-methylhistidine; AA, amino acids; BCAA, branched-chain amino acids; BCKA, branched-chain $\alpha$-keto acids; BW, body weight; CRP, C-reactive protein; EAA, essential AA; Ile, isoleucine; KIC, $\alpha$-ketoisocaproic acid, KMV, $\alpha$-keto- $\beta$-methylvaleric acid; Leu, leucine; MET; methionine; MNF, muscle net flux; MPF, muscle plasma flow; NEAA, non-essential AA; PAH, $p$-amino hippurate; Val, valine.

* Corresponding author: J. Peng, fax +86 278728 1378, email pengjian@mail.hzau.edu.cn 
elevation of muscle protein deposition and mass. Therefore, it is of great scientific interest to measure AA flux across skeletal muscle in vivo and clarify in what ways AA flux can be regulated $^{(9-11)}$. However, little has been known about the contribution of net AA flux to BCAA-induced increase of mass in skeletal muscle.

Apart from having a high protein synthesis capacity, skeletal muscle is also a major site for initiating extensive catabolism of BCAA $^{(12,13)}$. Skeletal muscle catabolises BCAA for the synthesis of alanine, glutamate, glutamine, aspartate and asparagine ${ }^{(14,15)}$. Among these AA, $97 \%$ of glutamate, $95 \%$ of aspartate and $67-70 \%$ of glutamine in the diets are catabolised by small intestine $^{(16,17)}$. It seems that BCAA catabolism in muscle may promote the resynthesis of these three non-essential AA (NEAA) to modulate intramuscular AA balance, and thereby enhances muscle protein synthesis. In addition, Leu transamination product $\alpha$-ketoisocaproic acid (KIC) can act as a nutrient signal to stimulate protein synthesis through activating translation initiation factors ${ }^{(5,18)}$ and to inhibit protein degradation through down-regulating the expression of proteolytic-related genes in skeletal muscle ${ }^{(19)}$. Thus, besides meeting the requirements for protein synthesis, supplementation of BCAA may affect protein turnover through their metabolism in skeletal muscle.

Taken together, we hypothesised that supplementation of BCAA to reduced-protein diet increases not only the arterial and intramuscular concentrations of BCAA but also their intramuscular catabolism, and thus contributes to elevated net AA fluxes across skeletal muscle, leading to the increase of muscle growth. Therefore, a hindlimb flux model was established by carotid artery, femoral artery and vein catheterizations to explore the impacts of BCAA supplementation on muscle net AA fluxes in young pigs fed reduced-protein diets. Metabolomics studies have been successfully applied to the investigation of the global changes of metabolites in animals in response to external stimuli (diet, diseases, drugs and environments), which could provide insights into the end points of metabolic fluxes in cells, tissues or the whole body ${ }^{(20,21)}$. In addition, hindlimb flux model enables the detection of net AA fluxes as well as specific AA metabolism in skeletal muscle. Therefore, the combination of metabolite profiling and AA flux model holds great promise for identifying potential metabolites and translating these metabolic changes into specific alterations in certain pathways at an organ level following a dietary intervention $^{(22)}$. Here, we performed a metabolomic analysis of femoral vein using HPLC-quadrupole time-of-flight MS (HPLCQTOF-MS) method to obtain global metabolic profiles in the outflow from skeletal muscle, and correlated the muscle net AA fluxes with the arterial and intramuscular concentrations of BCAA and the net production of branched-chain $\alpha$-keto acids (BCKA).

\section{Methods}

\section{Animals and diets}

The protocol of present study was approved by the Animal Care and Use Committee of College of Animal Sciences and Technology, Huazhong Agricultural University, and was carried out in accordance with the National Research Council's Guide for the Care and Use of Laboratory Animals. In all, fourteen 28-d-old barrows (Large White $\times$ Landrace) were individually housed in metabolic cages, and randomly assigned to receive one of two experimental diets: the reduced-crude protein (CP) diets supplemented with (treatment) or without (control) BCAA ( $n 7$ pigs/group), as we previously described ${ }^{(6)}$. The two diets were fortified with lysine (Lys), methionine (Met), threonine (Thr) and tryptophan (Trp) to satisfy the standardised ileal digestible (SID) AA requirements for pigs weighing $11-25 \mathrm{~kg}^{(23)}$, and had the same CP content of $16.7 \%$, which was $20 \%$ lower than that recommended by the National Research Council $(\mathrm{NRC})^{(24)}$. Control diet was formulated without addition of Val, Leu and Ile, but was supplemented with $0.42 \%$ alanine, which therefore was deficient of Val and Ile. The contents of SID Val, Ile and Leu in control diet were 86.8, 91.4 and 107.2\% of the $\mathrm{NRC}^{(23)}$ recommended contents, respectively. The treatment diet was formulated by supplementing $0.17 \%$ Ile, $0.24 \%$ Leu and $0.16 \%$ Val (all of 99\% purity; Amresco) to control diet to provide SID BCAA equal to the level in the diet with protein content $(20 \% \mathrm{CP})$ recommended by the $\mathrm{NRC}^{(24)}$. The ingredients of the diets and the amounts of added synthetic AA are shown in Table 1. All pigs had free access to feed and drinking water. Room temperature was maintained at $25-27^{\circ} \mathrm{C}$. One pig from control group was excluded because of unexpected death due to unknown causes at the beginning of week 1.

The remaining thirteen pigs were weighed after a 4-week acclimation period, and the feed intake was determined daily. As for animal growth, our previous work showed that the final body weight (BW) and average daily feed intake of BCAA-supplemented pigs were significantly greater than that of control pigs ${ }^{(6)}$. Then, catheters were placed into one carotid artery, femoral artery and vein on the left side of body as described below. The femoral artery catheter was used for infusion of $p$-amino hippurate (PAH) to measure plasma flow across the hindlimb muscle. The carotid artery and femoral vein catheters were used for blood collection.

\section{Surgery}

After overnight food deprivation, pigs were surgically implanted with catheters in one carotid artery $(2.41 \mathrm{~mm}$ outer diameter) under isoflurane anaesthesia and strict aseptic conditions as previously described ${ }^{(25,26)}$. The left femoral artery and vein were isolated, and cannulated with central venous catheters (1.4 mm outer diameter) as described by Ettrup et al. ${ }^{(27)}$. In brief, femoral artery and vein on the left side of body were identified in skin fold between gracilis and sartorius muscle where pulsation of superficial part of medial saphenous artery disappears. After making a longitudinal superficial skin incision cranial to this point, the underlying subcutaneous tissue was dissected using blunt-tip scissors. The two muscle groups were then separated with a small self-retaining tissue retractor. The artery was isolated for a length of approximately $1-2 \mathrm{~cm}$ using blunt dissection, and cannulated with central venous catheter. The femoral vein is located just medial to artery. After isolating the vein with blunt dissection, the vein was also cannulated. 
Table 1. Composition of experimental diets (as-fed basis)

\begin{tabular}{|c|c|c|}
\hline Items & Control & Treatmen \\
\hline \multicolumn{3}{|l|}{ Ingredients (\%) } \\
\hline Maize & 70.09 & 70.09 \\
\hline Soyabean meal & $10 \cdot 70$ & $10 \cdot 40$ \\
\hline Whey powder & 5.00 & 5.00 \\
\hline Fishmeal & 4.00 & 4.00 \\
\hline Concentrated soyabean protein & 5.00 & 5.00 \\
\hline Soyabean oil & 0.40 & 0.50 \\
\hline L-Lys. $\mathrm{HCl}$ & 0.48 & 0.48 \\
\hline DL-Met & 0.23 & 0.23 \\
\hline L-Thr & 0.22 & 0.23 \\
\hline L-Trp & 0.06 & 0.06 \\
\hline L-Ile & - & 0.17 \\
\hline L-Leu & - & 0.24 \\
\hline L-Val & - & 0.16 \\
\hline L-Ala & 0.42 & - \\
\hline Dicalcium phosphate & 1.30 & 1.30 \\
\hline Limestone & 0.60 & 0.60 \\
\hline Salt & 0.30 & 0.30 \\
\hline Bentonite & 0.20 & 0.24 \\
\hline Premix ${ }^{\star}$ & 1.00 & 1.00 \\
\hline \multicolumn{3}{|l|}{ Analysed composition (\%) } \\
\hline Crude protein & $16 \cdot 7$ & $16 \cdot 7$ \\
\hline Crude lipid & 8.48 & 8.95 \\
\hline Crude fibre & 2.34 & 2.54 \\
\hline Lys & 1.32 & 1.34 \\
\hline Met + Cys & 0.88 & 0.88 \\
\hline Thr & 0.87 & 0.92 \\
\hline Trp & 0.21 & 0.22 \\
\hline Ile & 0.60 & 0.81 \\
\hline Leu & 1.45 & 1.83 \\
\hline Val & 0.76 & 0.95 \\
\hline His & 0.74 & 0.77 \\
\hline Phe & 0.42 & 0.44 \\
\hline NE $(\mathrm{MJ} / \mathrm{kg}) \dagger$ & $10 \cdot 38$ & $10 \cdot 38$ \\
\hline
\end{tabular}

$\mathrm{NE}$, net energy.

* Provided per $\mathrm{kg}$ of diet (as-fed basis): vitamin A, $4500 \mu \mathrm{g}$; vitamin $\mathrm{D}_{3}, 37.5 \mu \mathrm{g}$; vitamin $E, 30 \mathrm{mg}$; vitamin $B_{1}, 3.2 \mathrm{mg}$; vitamin $B_{2}, 8 \mathrm{mg}$; vitamin $B_{6}, 4 \mathrm{mg}$; vitamin $B_{12}, 0.03 \mathrm{mg}$; vitamin $K_{3}, 3.2 \mathrm{mg}$; niacin, $34 \mathrm{mg}$; folate, $1.6 \mathrm{mg}$; pantothenic acid $18 \mathrm{mg}$; biotin, $0.2 \mathrm{mg}$; choline chloride, $500 \mathrm{mg}$; $\mathrm{Cu}, 150 \mathrm{mg}$; $\mathrm{Fe}, 120 \mathrm{mg}$ $\mathrm{Mn}, 45 \mathrm{mg}$; Zn, $90 \mathrm{mg}$; I, $0.6 \mathrm{mg}$; Se, $0.3 \mathrm{mg}$; Co, $0.3 \mathrm{mg}$; chlortetracycline, $35 \mathrm{mg}$ tiamulin $12 \mathrm{mg}$.

† Values for NE were calculated according to National Research Council(23).

The catheters were subsequently flushed with heparinised saline in order to maintain catheter patency. The femoral artery and vein were tightly ligated to secure the catheters. All thirteen pigs were successfully and accurately implanted with catheters in the carotid artery, femoral artery and vein.

\section{Postoperative management}

Postoperatively, pigs were placed in individual metabolism cages for recovery, and received daily intramuscular injection of penicillin sodium (6000 IU/kg BW) and streptomycin sulfate $(20 \mathrm{mg} / \mathrm{kg} \mathrm{BW})$ for $4 \mathrm{~d}$. On each day, the catheters were checked for patency, flushed and filled with heparinised saline solution. $10 \mathrm{ml}$ blood was drawn from femoral vein immediately before, and at days 2 and 5 after the surgery, and plasma was obtained after centrifugation at $4^{\circ} \mathrm{C}$ at $3000 \boldsymbol{g}$ for $10 \mathrm{~min}$ for C-reactive protein (CRP) analysis. There was no significant weight loss during the 4-d recovery phase (mean weight change of 0.59 (sD 1.08$) \mathrm{kg}$ ). At day 5 post surgery, twelve of the thirteen test pigs were in good health with well-kept catheters, with six pigs for each group. All these pigs achieved presurgery feed intake (1.01 (SD 0.3) kg/d), and the patency rates of the carotid arterial, femoral arterial and venous catheters reached $100 \%$. The catheters were subsequently used for infusion of $\mathrm{PAH}$ and blood collection.

\section{Infusion protocol and sample collection}

On day 5 post surgery, pigs were deprived of feed from 18.00 to 07.00 hours. At 06.55 hours, a continuous infusion of $1 \%(\mathrm{w} / \mathrm{v})$ $\mathrm{PAH}$ (sodium salt, diluted in sterile saline at $\mathrm{pH} 7.5$ ) was performed through the femoral artery catheter at a rate of $0.788 \mathrm{ml} /$ min for $9 \mathrm{~h}$ after an initial bolus of $19.1 \mathrm{ml} \mathrm{PAH} \mathrm{solution}{ }^{(25)}$. At 07.45 hours, baseline arterial and venous blood samples $(10 \mathrm{ml})$ were withdrawn into heparinised tubes. At 08.00 hours, pigs were offered with their corresponding diets at hourly intervals, and the diet was equivalent to $1 / 24$ of the daily intake $(45 \mathrm{~g} / \mathrm{kg}$ BW), which was continued for $8 \mathrm{~h}$ to achieve a constant fed state ${ }^{(25,28)}$. From 09.00 to 16.00 hours, arterial and venous blood samples $(10 \mathrm{ml})$ were simultaneously withdrawn every $1 \mathrm{~h}$, and immediately placed on ice. Plasma samples were obtained after centrifugation, and stored at $-80^{\circ} \mathrm{C}$ for the analysis of the concentrations of $\mathrm{PAH}, \mathrm{AA}$ and BCAA transamination products, including KIC, $\alpha$-keto- $\beta$-methylvaleric acid (KMV) and $\alpha$-ketoisovaleric acid (KIV) for Leu, Ile and Val, respectively.

Immediately after the completion of blood sample collection, pigs were killed with a venous injection of sodium pentobarbital (50 mg/kg BW) and sodium phenytoin ( $5 \mathrm{mg} / \mathrm{kg} \mathrm{BW})$. The biceps femoris muscle samples were rapidly removed and frozen in liquid nitrogen to be stored at $-80^{\circ} \mathrm{C}$ for subsequent AA and 3-methylhistidine (3-MH) analysis.

\section{Sample analysis}

Venous concentrations of CRP were analysed by a Porcine CRP ELISA Kit (Tridelta Development Limited). Concentrations of PAH in plasma samples were detected spectrophotometrically ${ }^{(25)}$ on an automated analysis system (Infinite M200 Pro; TEKAN). Free AA concentrations in plasma and muscle samples as well as the amount of free 3-MH in muscle samples, which was commonly used as an index of myofibrillar proteolysis, were determined by HPLC-quadrupole-orbitrap high resolution MS method using AQC derivatisation as described by Yin et al. ${ }^{(29)}$. Plasma BCKA was o-phenylenediamine derivatised, ethyl acetate extracted, and quantified by LC-MS as previously described $^{(30)}$.

\section{Metabolomic analysis using HPLC-quadrupole time-of-flight-MS}

Metabonomic profiling was performed by HPLC-QTOF-MS as previously described ${ }^{(31)}$ with some modifications. In brief, plasma samples were extracted with ice-cold acetonitrilemethanol solution $(1: 1, \mathrm{v} / \mathrm{v})$ at a $1: 4$ sample: extract solution ratio. After being vortexed and extracted for $2 \mathrm{~h}$ at $-20^{\circ} \mathrm{C}$, the samples were centrifuged at $13000 \mathrm{rpm}$ for $10 \mathrm{~min}$ at $4^{\circ} \mathrm{C}$. The supernatants were collected and evaporated to dryness in a vacuum concentrator. The residues were resuspended in $100 \mu \mathrm{l}$ of methanol-water (1:1), vortexed and centrifuged again at 
$13000 \mathrm{rpm}$ for $10 \mathrm{~min}$ at $4^{\circ} \mathrm{C}$. The supernatants were transferred to sampler vials for HPLC-QTOF-MS analysis in both positive and negative ionisation modes. The Masshunter Profinder software (version B.06.00; Agilent Technologies, Inc.) was employed for molecular feature extraction from the raw data. The data set was further processed with Mass Profiler Professional software (version 13.1.1; Agilent Technologies, Inc.) for multivariate analysis, such as principal component analysis (PCA). Differences in metabolic profiling between two groups were analysed by $t$ test and metabolites that met a criterion of $P<0.05$ and a fold change $>1.5$ were selected to generate formulas and search against the METLIN database.

\section{Calculations}

Plasma flow across hindlimb muscle was estimated using the PAH indicator dilution technique ${ }^{(32)}$, and was calculated using the following equation:

$$
\mathrm{MPF}=C_{i} \times \mathrm{IR} \times\left[\left(P A H_{v}-P A H_{a}\right) \times \mathrm{BW}\right]^{-1},
$$

where MPF is the muscle plasma flow (litre/kg per h), $C_{i}$ the $\mathrm{PAH}$ concentration in infusion solution $(\mathrm{g} / \mathrm{l})$, IR the infusion rate (litre/h), $P A H_{v}$ and $P A H_{a}$ the concentrations (g/l) of $\mathrm{PAH}$ detected in the femoral vein and carotid artery, respectively, and $\mathrm{BW}$ the body weight $(\mathrm{kg})$.

The net AA or BCKA fluxes across hindlimb muscle were calculated as follows:

$$
\mathrm{MNF}=\mathrm{MPF} \times\left(C_{a}-C_{v}\right),
$$

where MNF is the muscle net flux ( $\mu \mathrm{mol} / \mathrm{kg}$ per $\mathrm{h}$ ), MPF the muscle plasma flow (litre/kg per h), and $C_{a}$ and $C_{v}$ the carotid arterial and femoral venous plasma concentrations $(\mu \mathrm{mol} / \mathrm{l})$ of AA or BCKA, respectively. Therefore, a positive flux means uptake and a negative flux means production of AA or BCKA.

\section{Statistical analysis}

The effects of diet (control $v$. treatment) and time (baseline and eight time point intervals after feeding) on muscle plasma flow (MPF), muscle net fluxes (MNF) and plasma concentrations of CRP and different sums of AA were determined using two-way repeated-measures ANOVA. Post hoc testing was performed using the Bonferroni $t$ test for multiple comparisons with baseline and control. Moreover, arterial AA concentrations and MNF of AA and BCKA in fed state were calculated by the mean values of samples collected between 4 and $8 \mathrm{~h}$ after feeding. Significant differences among dietary groups for these data and intramuscular AA and 3-MH concentrations were tested using Student's $t$ test. Effect of diet (control $v$. treatment), feeding state (fasted $v$. fed) and their interaction on MPF (mean values during $1-8 \mathrm{~h}$ for the fed state) was analysed using two-way ANOVA with a $2 \times 2$ factorial arrangement of treatments. Correlation analysis of MNF of total essential AA (EAA), NEAA and AA and concentrations of arterial and intramuscular BCAA, and net BCKA production in fed state was performed to determine whether a significant relationship existed between these variables. All analyses were performed using the SAS 8.0. Data were expressed as mean values with their standard errors.
Differences were considered as significant at $P \leq 0.05$ and a trend when $0.05<P<0 \cdot 10$.

\section{Results}

\section{C-reactive protein}

Venous concentrations of CRP at day 2 after surgery in both groups were significantly increased when compared with baseline (day 0) $(P<0.05)$, and fell back to the baseline value at day 5 after surgery (Fig. 1). However, no differences were observed between groups at each time point.

\section{Muscle plasma flow}

Pigs in both groups showed similar time course patterns of MPF after the start of feeding (Fig. 2(a)). MPF was rapidly and significantly increased within $1 \mathrm{~h}$ and continued to be elevated at 2 and $3 \mathrm{~h}$ in treatment group compared with baseline $(P<0.05)$. There was a trend of increase in MPF at $3 \mathrm{~h}$ in control group relative to baseline $(P=0 \cdot 06)$. No group differences were observed at every time point. A further two-way ANOVA showed that MPF was higher in fed state than in fasted state ( $P<0.05$; Fig. 2(b)), but there was no significant effect of dietary treatment or interaction between diet and feeding state on MPF.

\section{Amino acid concentrations in arterial plasma}

Changes of AA concentrations in arterial plasma at different time points after the start of feeding are presented in Fig. 3. Compared with baseline, significant increases were observed for arterial concentrations of total BCAA at 1, 2, $7 \mathrm{~h}$ and total AA at $7 \mathrm{~h}$ in treatment group, and total EAA at 6 and $7 \mathrm{~h}$ in both groups $(P<0 \cdot 05)$. However, the arterial concentration of total NEAA did not differ at different time points in both groups. Furthermore, pigs in treatment group showed enhanced arterial concentration of total BCAA at 5, 7 and $8 \mathrm{~h}$ compared with the control $(P<0.05)$, but no differences were detected regarding total EAA, NEAA and AA at any time points between two groups.

The mean arterial concentrations of individual AA and total BCAA, EAA, NEAA and AA in fed state are presented in Table 2.

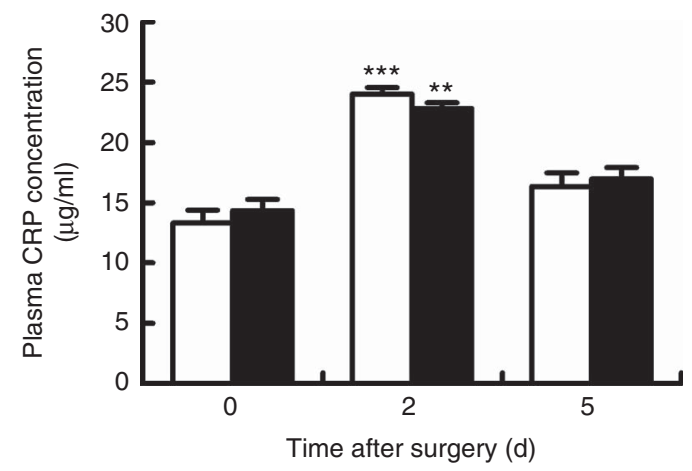

Fig. 1. Venous concentrations of C-reactive protein (CRP) in young pigs fed reduced-protein diets without (control, $\square$ ) or with (treatment, $\square$ ) supplemental branched-chain amino acids immediately before, and at days 2 and 5 after surgery. Values are means (n 6/group), with standard errors represented by vertical bars. ${ }^{\star \star} P<0.01,{ }^{\star \star \star} P<0.001 \mathrm{v}$. baseline (day 0 ). 

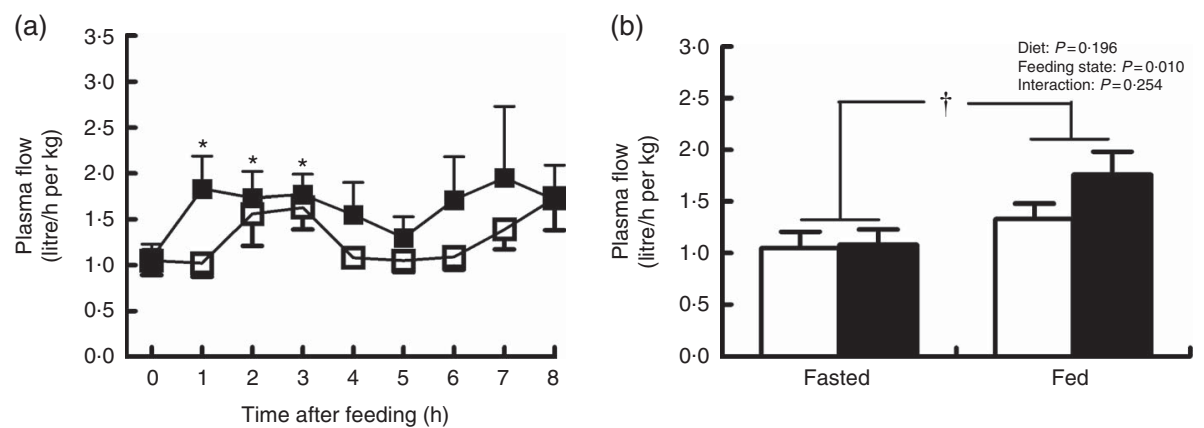

Fig. 2. Plasma flow across hindlimb muscle in young pigs fed reduced-protein diets without (control, $\square$ ) or with (treatment, $\square$ ) supplemental branched-chain amino acids at hourly intervals (a) and in fasted and fed state (b). Values are means ( $n$ 6/group), with standard errors represented by vertical bars. ${ }^{*} P<0.05 v$. baseline $(t=0)$ based on repeated-measure ANOVA. $\dagger P<0.05 \mathrm{v}$. fasted state based on two-way ANOVA with a $2 \times 2$ factorial arrangement of treatments.
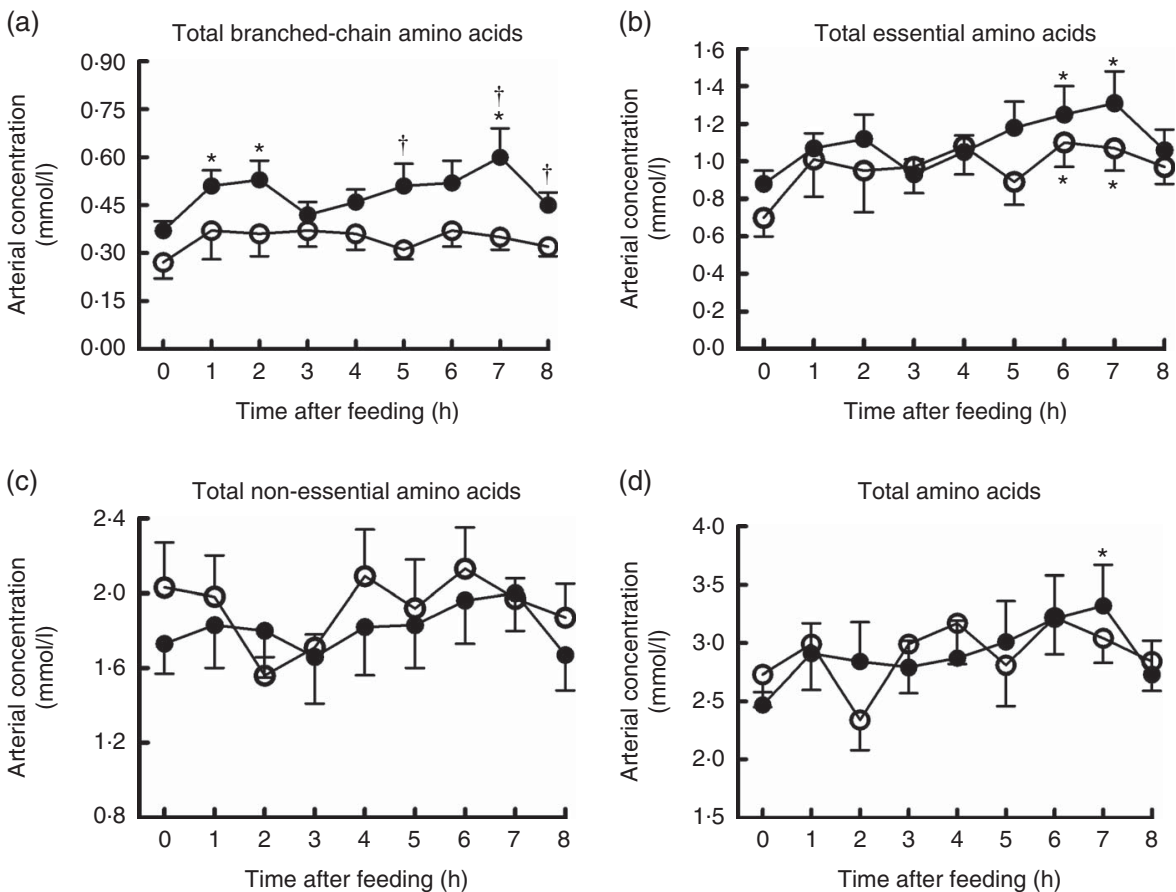

Fig. 3. Time course patterns of arterial concentrations of total branched-chain amino acids (BCAA) (a), essential amino acids (b), non-essential amino acids (c) and amino acids (d) in young pigs fed reduced-protein diets without (control, $O$ ) or with (treatment, $\bigcirc$ ) supplemental BCAA. Values are means $(n 6 /$ group), with standard errors. ${ }^{*} P<0.05 \mathrm{v}$. baseline $(t=0)$. $† P<0.05 \mathrm{v}$. control group at the corresponding time point.

There were no differences in arterial concentrations of total EAA, NEAA and AA between two groups, but total BCAA concentration was higher in treatment group than in control group $(P<0.05)$. As expected, dietary BCAA supplementation enhanced the concentrations of individual BCAA $(P<0.05)$. However, lower concentrations of phenylalanine and serine $(P<0.05)$ and a trend $(P=0 \cdot 10)$ for lower cysteine concentration were detected after BCAA supplementation, even though their dietary contents were similar between two groups.

\section{Free amino acid and 3-methylhistidine concentrations in muscle}

In line with elevated arterial concentrations, the concentrations of free individual and total BCAA in biceps femoris muscle were also increased by BCAA supplementation $(P<0 \cdot 05$; Fig. 4(a)), whereas the concentration of serine was unexpectedly decreased $(P<0.05$; Fig. 4(b)). There was a trend for the decrease of histidine $(P=0.08)$ and asparagine $(P=0.06)$ concentrations in treatment group. Intramuscular concentrations of other individual AA and total EAA, NEAA and AA did not differ between two groups (Fig. 4(c)). Interestingly, intramuscular concentration of 3-MH, which is commonly used as an index of myofibrillar proteolysis, was lower in treatment group than in control group $(P<0 \cdot 05$; Fig. $4(d))$.

\section{Muscle net fluxes of amino acid and branched-chain amino acids transamination products}

The time course patterns of the MNF of total BCAA, EAA, NEAA and AA after the start of feeding were similar in both groups (Fig. 5). Compared with baseline, treatment group showed 
elevated MNF of total BCAA, EAA and NEAA at 6 and $7 \mathrm{~h}$ as well as total AA within $4-7 \mathrm{~h}(P<0.05)$. With regard to control group, MNF were higher only for total BCAA at $7 \mathrm{~h}$, but lower

Table 2. Arterial concentrations ( $\mathrm{mmol} / \mathrm{l})$ of individual and different sums of amino acids (AA) in young pigs fed reduced-protein diets without (control) or with (treatment) supplemental branched-chain AA (BCAA) in fed state* (Mean values with their pooled standard errors; $n$ 6/group)

\begin{tabular}{|c|c|c|c|c|}
\hline Items & Control & Treatment & SEM & $P$ \\
\hline \multicolumn{5}{|l|}{ EAA } \\
\hline Ile & 0.07 & 0.11 & 0.02 & 0.042 \\
\hline Leu & 0.14 & 0.18 & 0.02 & 0.047 \\
\hline Val & 0.14 & 0.22 & 0.03 & 0.021 \\
\hline Arg & 0.09 & 0.10 & 0.01 & 0.463 \\
\hline His & 0.03 & 0.03 & 0.00 & 0.635 \\
\hline Lys & 0.21 & 0.21 & 0.03 & 0.995 \\
\hline Met & 0.06 & 0.05 & 0.01 & 0.308 \\
\hline Phe & 0.09 & 0.08 & 0.01 & 0.033 \\
\hline Thr & 0.15 & 0.15 & 0.03 & 0.790 \\
\hline Tryp & 0.06 & 0.06 & 0.01 & 0.856 \\
\hline \multicolumn{5}{|l|}{ NEAA } \\
\hline Ala & 0.20 & 0.16 & 0.03 & $0 \cdot 218$ \\
\hline Asp & 0.01 & 0.01 & 0.00 & 0.993 \\
\hline Asn & 0.19 & 0.14 & 0.04 & 0.257 \\
\hline Cys & 0.05 & 0.04 & 0.01 & 0.095 \\
\hline Glu & 0.22 & 0.24 & 0.05 & 0.689 \\
\hline Gln & 0.34 & 0.32 & 0.05 & 0.753 \\
\hline Gly & 0.59 & 0.56 & 0.09 & 0.689 \\
\hline Pro & 0.20 & 0.20 & 0.03 & 0.809 \\
\hline Ser & 0.13 & 0.11 & 0.01 & 0.023 \\
\hline Tyr & 0.05 & 0.06 & 0.01 & 0.800 \\
\hline Total BCAA & 0.34 & 0.50 & 0.06 & 0.032 \\
\hline Total EAA & 1.02 & $1 \cdot 17$ & 0.16 & 0.356 \\
\hline Total NEAA & 2.00 & 1.86 & 0.28 & 0.631 \\
\hline Total AA & 3.02 & 3.03 & 0.41 & 0.982 \\
\hline
\end{tabular}

EAA, essential AA; NEAA, non-essential AA.

${ }^{*}$ Results are based on samples collected between 4 and $8 \mathrm{~h}$ after the start of the feeding protocol. Differences were considered significant at $P<0.05$. for total BCAA and EAA at $2 \mathrm{~h}$ compared with baseline $(P<0.05)$. Moreover, MNF of total BCAA, EAA, NEAA and AA were detected to be higher at $7 \mathrm{~h}$ in treatment group than in control group $(P<0 \cdot 05)$.

The mean MNF of AA and BCAA transamination products in fed state are shown in Table 3. The treatment group showed higher positive net fluxes of total EAA, NEAA and AA as well as BCAA and their metabolites including alanine, glutamate and glutamine than control group $(P<0.05)$. Meanwhile, BCAA supplementation also increased the MNF of histidine, Met and several functional NEAA including glycine, proline and serine $(P<0.05)$, whereas no differences were observed between two groups for other AA. Interestingly, in fed state, both groups showed net uptake of almost all AA, except for asparagine and glutamine; besides, they also showed net production of BCKA, especially KIC, indicating that BCAA were catabolised in skeletal muscle. The first step of BCAA catabolism is transamination, which leads to the formation of KIC, KMV and KIV for Leu, Ile and Val, respectively. In accordance with the increased muscle net AA fluxes, net productions of KIC and KMV were greater in treatment group than in control group $(P<0.05$; Table 3). However, there was no difference in net KIV production between two groups.

\section{Metabolomic profiling}

PCA was employed to identify the possible relationships within classes of data. Data were visualised by plotting PCA scores, where each point on the plot represents a single sample. PCA score plot showed an excellent separation of plasma samples between the control and treatment groups (date not shown). Metabolomes of the plasma from two groups were differentially expressed, and most of these compounds were AA and their
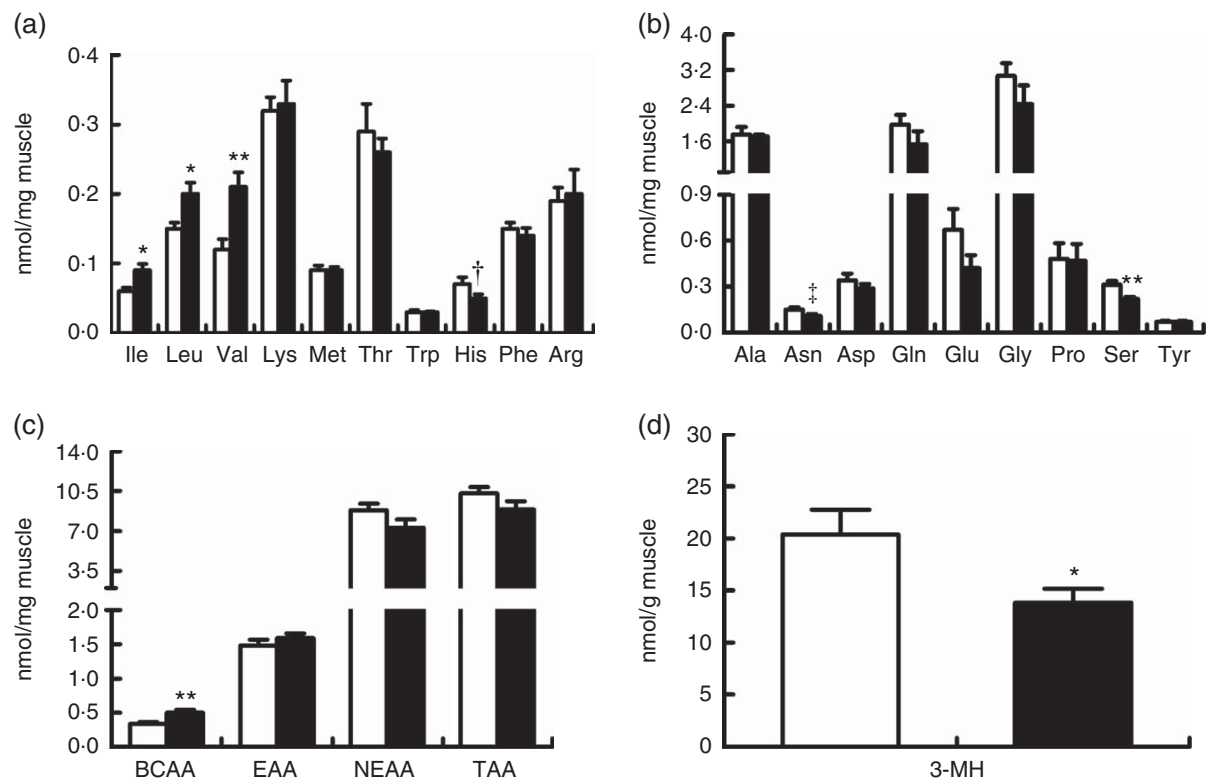

Fig. 4. Concentrations of free amino acids and 3-methylhistidine (3-MH) in biceps femoris muscle at the end of an 8-h feeding period in young pigs fed reduced-protein diets without (control, $\square$ ) or with (treatment, $\square$ ) supplemental branched-chain amino acids (BCAA). Individual essential amino acids (EAA) (a), individual non-essential amino acids (NEAA) (b), different sums of amino acids (c) and 3-MH (d) are shown. Values are means ( $n$ 6/group), with standard errors represented by vertical bars. ${ }^{\star} P<0.05,{ }^{\star *} P<0.01, \dagger P=0.08, \ddagger P=0.06$ v. control group. TAA, total AA. 
(a)

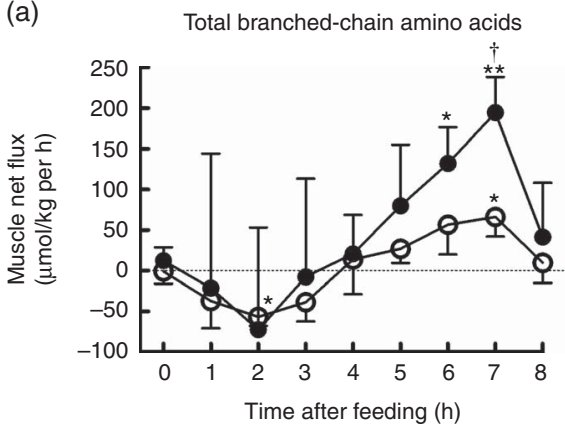

(c)

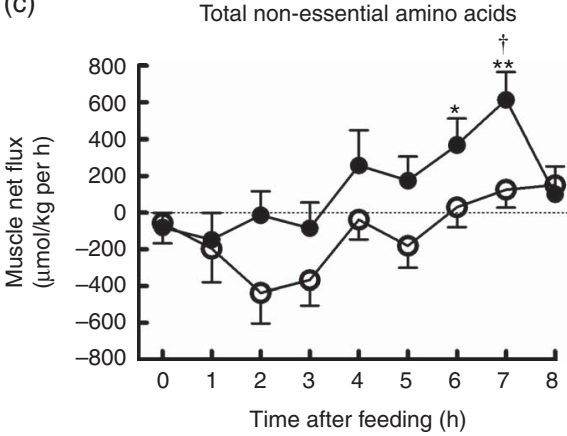

(b)

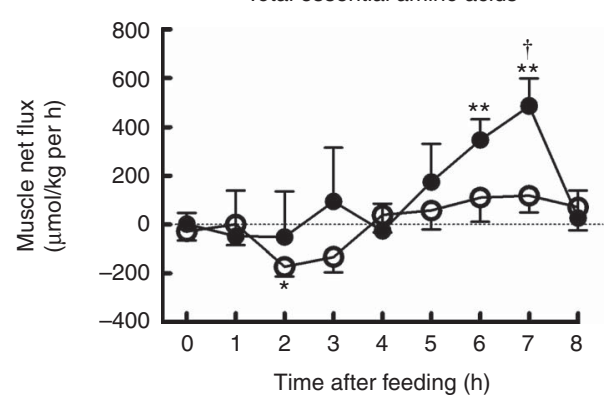

(d)

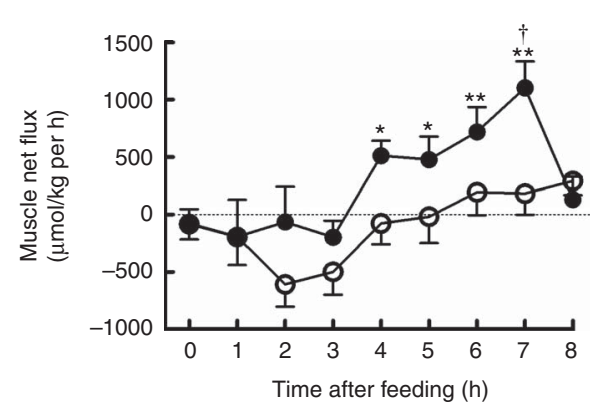

Fig. 5. Time course patterns of net fluxes of total branched-chain amino acids (BCAA) (a), essential amino acids (b), non-essential amino acids (c) and amino acids (d) across hindlimb muscle in young pigs fed reduced-protein diets without (control, $\bigcirc$ ) or with (treatment, $\bigcirc$ ) supplemental BCAA. Values are means ( $n$ 6/group), with standard errors. ${ }^{\star} P<0.05 \mathrm{v}$. baseline $(t=0)$. ${ }^{\star \star} P<0.01 \mathrm{v}$. baseline $(t=0), \dagger P<0.05 \mathrm{v}$. control group at corresponding time point.

metabolites (Table 4). Compared with control group, pigs in treatment group displayed increases in BCAA and their transamination products BCKA, but decreases in Met, tryptophane, asparagine, glutamine, serine and proline $(P<0.05)$. The trends of AA, except for those of BCAA, were consistent with the results of intramuscular AA concentrations, but were inconsistent with the results of muscle net AA fluxes. Moreover, a number of metabolites of lipid metabolism were more abundant in treatment group than in control group $(P<0.05)$. Other metabolites, including purine, 6-hydroxyniacin, coenzyme Q9 and tributyrin, were also increased after BCAA supplementation $(P<0 \cdot 05)$.

\section{Correlations}

The $r$ correlation values are outlined in Table 5. There were significant positive correlations between the MNF of total EAA, NEAA and AA and the arterial concentrations of Leu and Ile $(P<0 \cdot 05)$. Moreover, the net fluxes of total EAA and AA were significantly positively correlated with the arterial concentration of Val $(P<0 \cdot 05)$. However, no significant relationships were found between the MNF of total EAA, NEAA and AA and the intramuscular concentrations of individual BCAA. As BCKA may potentially stimulate muscle protein synthesis, the correlations between the net fluxes of total EAA, NEAA and AA and the net productions of BCKA in muscle were also calculated. There were also significant positive relationships between the MNF of total EAA, NEAA and AA and the net production of KIC and KMV $(P<0.05)$. These correlations indicated that muscle net AA fluxes are highly and positively correlated with arterial BCAA concentrations and BCAA catabolism in the muscle.

\section{Discussion}

To our knowledge, this is the first study to investigate the roles of BCAA in regulating net AA fluxes across skeletal muscle and the related mechanisms. In this study, supplementation of BCAA to reduced-protein diet increased the MNF of total EAA, NEAA and AA (Table 3), which would facilitate the increase of muscle growth. Furthermore, the MNF of BCAA and their metabolites (including alanine, glutamate and glutamine) as well as histidine, Met and several functional NEAA (including glycine, proline and serine) were also increased after BCAA supplementation. Metabolomic profiling revealed a BCAArelated metabolite signature that was suggestive of increased intramuscular catabolism of BCAA induced by BCAA supplementation (Table 4). BCAA catabolism promotes the synthesis of BCKA and several NEAA, especially glutamine, both of which may contribute to the increase of muscle net AA fluxes.

\section{Technical advantages}

Skeletal muscle is the main site that synthesises protein with AA. The anabolic effect of BCAA on the growth of muscles including hindlimb biceps femoris muscle in pigs had been clarified in our recent previous study ${ }^{(6)}$. Therefore, the major goal of the present study was to determine the MNF of AA, and whether they are responsive to BCAA supplementation. To date, muscle net AA fluxes have been successfully detected by implanting catheters into abdominal aorta and inferior vena cava (inferior to the renal veins and superior to the common iliac vein) in several studies $^{(10,11)}$. However, this hindquarter flux model has several shortcomings, including difficulty of implanting catheters, a high 
Table 3. Net fluxes ( $\mu \mathrm{mol} / \mathrm{kg}$ per $\mathrm{h}$ ) of amino acids (AA) and branchedchain $A A(B C A A)$ transamination products across hindlimb muscle of young pigs fed reduced-protein diets without (control) or with (treatment) supplemental BCAA in fed state*

(Mean values with their pooled standard errors; $n$ 6/group)

\begin{tabular}{|c|c|c|c|c|}
\hline Items & Control & Treatment & SEM & $P$ \\
\hline \multicolumn{5}{|l|}{ EAA } \\
\hline Ile & 7.83 & $26 \cdot 24$ & $8 \cdot 15$ & 0.047 \\
\hline Leu & 14.32 & 40.57 & $11 \cdot 30$ & 0.042 \\
\hline Val & 6.51 & 32.44 & $10 \cdot 72$ & 0.036 \\
\hline Arg & $13 \cdot 86$ & 29.04 & 13.48 & 0.286 \\
\hline His & 1.56 & $6 \cdot 74$ & $2 \cdot 29$ & 0.048 \\
\hline Lys & 23.81 & 30.47 & 10.09 & 0.524 \\
\hline Met & $2 \cdot 12$ & 9.68 & 3.17 & 0.038 \\
\hline Phe & 2.64 & 6.65 & 7.41 & 0.600 \\
\hline Thr & $20 \cdot 39$ & 33.80 & 11.23 & 0.260 \\
\hline Trp & $2 \cdot 39$ & $10 \cdot 27$ & 7.75 & 0.408 \\
\hline \multicolumn{5}{|l|}{ NEAA } \\
\hline Ala & -7.37 & 17.34 & $10 \cdot 32$ & 0.038 \\
\hline Asp & 1.09 & $1 \cdot 26$ & 1.91 & 0.930 \\
\hline Asn & $-99 \cdot 70$ & -64.78 & 55.67 & 0.545 \\
\hline Cys & 4.07 & $12 \cdot 50$ & 17.00 & 0.631 \\
\hline Glu & 68.04 & 129.41 & 20.54 & 0.014 \\
\hline Glx & $-119 \cdot 16$ & -26.51 & 39.87 & 0.043 \\
\hline Gly & -43.50 & $42 \cdot 44$ & 33.91 & 0.030 \\
\hline Pro & $2 \cdot 14$ & $32 \cdot 18$ & 9.83 & 0.012 \\
\hline Ser & $21 \cdot 74$ & $45 \cdot 63$ & 9.69 & 0.033 \\
\hline Tyr & $2 \cdot 74$ & $8 \cdot 17$ & 3.86 & 0.190 \\
\hline Total BCAA & $22 \cdot 30$ & 99.03 & $27 \cdot 22$ & 0.018 \\
\hline Total EAA & 37.69 & 207.35 & 44.04 & 0.003 \\
\hline Total NEAA & 71.31 & 264.55 & 64.08 & 0.022 \\
\hline Total AA & $122 \cdot 87$ & $516 \cdot 26$ & $135 \cdot 26$ & 0.016 \\
\hline \multicolumn{5}{|c|}{ Branched-chain $a$-keto acids } \\
\hline $\mathrm{KIC}$ & -1.48 & $-13 \cdot 23$ & 4.00 & 0.015 \\
\hline KMV & $1 \cdot 11$ & -3.98 & $1 \cdot 16$ & 0.001 \\
\hline KIV & -0.46 & 0.03 & $1 \cdot 27$ & 0.711 \\
\hline
\end{tabular}

EAA, essential AA; NEAA, non-essential AA; KIC, $a$-ketoisocaproic acid; KMV, $a$-keto- $\beta$-methylvaleric acid; KIV, $a$-ketoisovaleric acid.

* Results are based on samples collected between 4 and $8 \mathrm{~h}$ after the start of feeding. Differences were considered significant at $P<0.05$. A positive flux means uptake and a negative flux means production.

risk of surgical-wound infection, and the fact that venous AA output from both hindquarter and several pelvic organs is also included in the estimation. Alternatively, hindlimb flux model by femoral artery and vein catheterization is more easily operated with a low risk of wound infection ${ }^{(27)}$. In this study, the surgical procedures for placing chronic catheters into one carotid artery, femoral artery and vein of pigs took approximately $1.5 \mathrm{~h} /$ animal, which is less than that required for hindquarter flux model.

CRP is often used as an indicator of inflammatory status after surgery ${ }^{(33)}$. In the present study, the plasma concentrations of CRP and feed intake in both groups were restored to basal levels at day 5 after surgery, indicating that the pigs did not suffer from inflammation and were in good health. Moreover, CRP concentration was not affected by BCAA supplementation. Thus, based on the samples collected at day 5 after surgery, any observed differences should be attributed to BCAA administration rather than to the changes in inflammatory state.

\section{Muscle net amino acid fluxes}

Few reports are available on the measurement of muscle net AA fluxes using hindlimb flux model in pigs. The results obtained using this model in the present study showed that pigs had positive MNF of total BCAA, EAA, NEAA and AA, and almost all individual AA except for glutamine and asparagine in both groups in fed state (Table 3), which supports the finding that feeding can induce the stimulation of protein synthesis in skeletal muscle ${ }^{(34,35)}$. Release of glutamine and asparagine from muscle even in fed state was also found in previous studies, which has important functions in extramuscular tissues ${ }^{(14,36)}$

It is noteworthy that the MNF of total EAA, NEAA and AA in pigs fed diet supplemented with BCAA increased significantly (Table 3), which would contribute to the elevation of muscle growth in pigs ${ }^{(6)}$. Moreover, dietary BCAA supplementation increased the MNF of BCAA and their metabolites including alanine, glutamate and glutamine. In addition to satisfying the requirement of protein synthesis, BCAA are also extensively utilised by muscle to produce alanine, glutamate, glutamine, aspartate and asparagine ${ }^{(14,15)}$. This is supported by our results that BCAA accounted for $50-60 \%$ of the EAA extracted by muscle, whereas they only accounted for $38 \%$ of EAA in porcine muscle proteins ${ }^{(37)}$. Moreover, the synthesis of alanine, glutamate and glutamine from BCAA catabolism may explain the finding that the intramuscular concentrations of these three NEAA are not affected by BCAA supplementation despite of the increase of their net fluxes (Table 3). Although skeletal muscle catabolises BCAA also for the synthesis of aspartate and $\operatorname{asparagine}^{(13,15)}$, no differences in net fluxes of these two AA were observed between groups in this study, which was probably due to the large pooled standard error of the mean (Table 3). As $97 \%$ of glutamate, $95 \%$ of aspartate and $67-70 \%$ of glutamine in the diet are catabolised by pig small intestine in the first pass ${ }^{(16,17)}$, it is likely that the extensive catabolism of BCAA in muscle may promote the resynthesis of these three AA to modulate intramuscular AA balance, and thereby increases muscle net AA fluxes.

Glutamate and ammonia are combined by glutamine synthetase to produce glutamine, which is required for maintaining an extremely high intramuscular concentration of glutamine ${ }^{(38)}$. This high intramuscular glutamine level plays an important role in promoting protein synthesis and preventing protein degradation in the muscle $e^{(14,39)}$. It has been demonstrated that the increased production of glutamine from BCAA catabolism and protein mobilisation and the export of glutamine by muscle occur in a variety of atrophying conditions ${ }^{(40)}$. Glutamine is simultaneously extracted by liver, gut and lymphocytes, which is of physiological importance ${ }^{(41)}$. Interestingly, in this study, the release of glutamine from skeletal muscle was reduced after BCAA supplementation (Table 3), which might be required for the sustaining elevation of protein synthesis and reduction of protein degradation that lead to the elevation of protein deposition in skeletal muscle. The decrease of muscle protein degradation after BCAA supplementation was demonstrated by the reduction in intramuscular concentration of $3-\mathrm{MH}$ (Fig. 4(d)). These results indicate that dietary supplementation of BCAA would be an effective way to improve muscle protein balance through increasing glutamine synthesis from BCAA and thus inhibiting protein mobilisation.

In addition, as the catabolism of histidine, glycine, proline and serine in muscle is negligible ${ }^{(42,43)}$, the increased extraction 
Table 4. Metabolites that differed in femoral vein plasma between young pigs fed branched-chain amino acids (BCAA)-supplemented treatment diet and those unsupplemented control diet

\begin{tabular}{|c|c|c|c|c|}
\hline Metabolites & Theoretical exact $(\mathrm{m} / \mathrm{z})$ & Mean measured $(m / z)$ & Mass error (ppm) & Fold change* \\
\hline \multicolumn{5}{|l|}{ Amino acids } \\
\hline Val & 118.0863 & 118.0867 & 3.39 & 1.58 \\
\hline Leu & $132 \cdot 1019$ & $132 \cdot 1016$ & $-2 \cdot 27$ & 1.23 \\
\hline Ile & $132 \cdot 1019$ & $132 \cdot 1021$ & 1.51 & 1.38 \\
\hline Met & 150.0583 & $150 \cdot 0585$ & 1.33 & -1.38 \\
\hline Trp & 205.0972 & 205.0975 & 1.46 & -1.78 \\
\hline Asn & 133.0608 & 133.0604 & -3.01 & -1.55 \\
\hline Gln & $147 \cdot 0764$ & 147.0759 & -3.40 & -1.23 \\
\hline Ser & 106.0499 & $106 \cdot 0495$ & -3.77 & -1.38 \\
\hline Pro & $116 \cdot 0706$ & $116 \cdot 0710$ & 3.45 & $-6 \cdot 79$ \\
\hline \multicolumn{5}{|l|}{ Branched-chain $a$-keto acids } \\
\hline$a$-Ketoisovaleric acid & $115 \cdot 0401$ & $115 \cdot 0398$ & $-2 \cdot 61$ & 1.99 \\
\hline$a$-Ketoisocaproic acid & $129 \cdot 0557$ & $129 \cdot 0552$ & -3.87 & 1.59 \\
\hline$\alpha$-Keto- $\beta$-methylvaleric acid & 129.0557 & 129.0555 & -1.55 & 1.86 \\
\hline \multicolumn{5}{|l|}{ Lipid metabolism-related metabolites } \\
\hline 7E,9Z-dodecadienal & $181 \cdot 1587$ & $181 \cdot 1591$ & $2 \cdot 21$ & $15 \cdot 37$ \\
\hline Dodecanamide & $200 \cdot 2009$ & $200 \cdot 2012$ & 1.50 & $2 \cdot 31$ \\
\hline Palmitoleic acid & $255 \cdot 2319$ & $255 \cdot 2324$ & 1.96 & $32 \cdot 17$ \\
\hline Palmitic amide & $256 \cdot 2635$ & $256 \cdot 2641$ & 2.34 & 6.95 \\
\hline $9 \mathrm{Z}, 12 \mathrm{Z}, 15 \mathrm{E}-$ octadecatrienoic acid & $279 \cdot 2319$ & $279 \cdot 2322$ & 1.07 & 4.49 \\
\hline $6 \mathrm{E}, 9 \mathrm{E}-\mathrm{octadecadienoic}$ acid & $281 \cdot 2475$ & $281 \cdot 2487$ & 4.27 & 1.67 \\
\hline 16Z-octadecenoic acid & $283 \cdot 2632$ & $283 \cdot 2636$ & 1.41 & $15 \cdot 86$ \\
\hline EPA & 303.2319 & 303.2325 & 1.98 & 36.40 \\
\hline Glycidyl oleate & $339 \cdot 2894$ & $339 \cdot 2899$ & 1.47 & $7 \cdot 64$ \\
\hline Heneicosanedioic acid & $357 \cdot 2999$ & $357 \cdot 3013$ & 3.92 & $22 \cdot 78$ \\
\hline \multicolumn{5}{|l|}{ Others } \\
\hline Purine & 121.0509 & 121.0514 & $4 \cdot 13$ & 3.56 \\
\hline 6-hydroxyniacin & 140.0342 & 140.0344 & 1.43 & 6.46 \\
\hline Coenzyme Q9 & 793.6140 & 793.6159 & $2 \cdot 37$ & $5 \cdot 11$ \\
\hline Tributyrin & $301 \cdot 1657$ & $301 \cdot 1646$ & -3.65 & $20 \cdot 14$ \\
\hline
\end{tabular}

ppm, Parts per million.

* Fold change, which was based on the normalised data, was defined as the fold difference in the observed concentrations between control and treatment groups. A positive number for a fold change indicates that the value for treatment group was greater than control group, whereas the opposite is indicated by a negative number.

Table 5. Correlations between muscle net fluxes of different sums of amino acids (AA) and concentrations of arterial and intramuscular branched-chain AA (BCAA), and net branched-chain $a$-keto acids (BCKA) productions of young pigs in fed stateł

\begin{tabular}{|c|c|c|c|}
\hline & \multicolumn{3}{|c|}{ Muscle net flux $(\mu \mathrm{mol} / \mathrm{kg}$ per $\mathrm{h})$} \\
\hline & Total EAA & Total NEAA $(r)$ & Total AA \\
\hline \multicolumn{4}{|c|}{ Arterial concentrations $(\mathrm{mmol} / \mathrm{l})$} \\
\hline Leu & $0.756^{\star *}$ & $0.774^{\star *}$ & $0.697^{*}$ \\
\hline Ile & $0.799^{* *}$ & $0.743^{\star *}$ & $0.674^{*}$ \\
\hline Val & $0.807^{* *}$ & $0.576 \dagger$ & $0.607^{*}$ \\
\hline \multicolumn{4}{|c|}{ Intramuscular concentrations (nmol/mg muscle) } \\
\hline Leu & 0.148 & 0.436 & 0.208 \\
\hline Ile & 0.416 & 0.497 & 0.315 \\
\hline Val & 0.522 & 0.477 & 0.413 \\
\hline \multicolumn{4}{|c|}{ Muscle net production ( $\mu \mathrm{mol} / \mathrm{kg}$ per $\mathrm{h}$ ) } \\
\hline $\mathrm{KIC}$ & $0 \cdot 763^{*}$ & $0.793^{* *}$ & $0.800^{* *}$ \\
\hline KMV & $0.639^{*}$ & $0.749^{*}$ & $0.625^{*}$ \\
\hline KIV & 0.127 & -0.182 & 0.154 \\
\hline
\end{tabular}

EAA, essential AA; NEAA, non-essential AA; KIC, a-ketoisocaproic acid; KMV, $a$-keto- $\beta$-methylvaleric acid; KIV, $a$-ketoisovaleric acid.Significant correlation: ${ }^{*} P<0.05,{ }^{*} P<0.01$. Trend towards statistical significance, $+P=0.06$.

$\ddagger$ Results are based on samples collected between 4 and $8 \mathrm{~h}$ after the start of the feeding protocol $(n$ 12).

of these four AA by muscle may be totally used for protein synthesis, which contributes to the increase of protein synthesis after BCAA supplementation. Although Met can be transaminated and is also subjected to transulfuration in muscle, the pathway is quantitatively unimportant ${ }^{(44,45)}$.

\section{Modulation of muscle net amino acid fluxes by substrate concentrations}

BCAA, particularly Val and Ile, are found to be limiting AA for growth following Lys, Met, Thr and Trp, and deficiency of dietary BCAA impairs the growth of young pigs ${ }^{(46,47)}$. As BCAA are EAA that cannot be synthesised de novo in animal cells ${ }^{(48)}$, they must be obtained from the diet. Even though $30-50 \%$ of dietary BCAA are degraded by pig small intestine in the first pass ${ }^{(16,17)}$, it seems that the amounts of these AA that enter blood circulation are positively correlated with their amounts in the diets ${ }^{(47,49-51)}$. In the present study, dietary BCAA supplementation, as expected, significantly increased both the arterial and intramuscular concentrations of individual BCAA in pigs (Table 2 and Fig. 4), which may provide sufficient substrates for protein synthesis in the muscle. It has been shown that the increase of blood AA concentrations occurs faster than can be accommodated by a stimulation of membrane transport ${ }^{(52)}$, and when the demand for AA in muscle protein synthesis outstrips AA supply, intramuscular AA concentrations would decrease, even though the influx to the intracellular compartment increases ${ }^{(53)}$. These findings may explain our observation that 
the muscle net AA fluxes were strongly and positively correlated with arterial BCAA concentrations rather than with intramuscular BCAA concentrations (Table 5). For other AA, as their dietary contents were similar between two groups, the arterial concentrations of these AA (except for phenylalanine, serine and cysteine) were not affected by BCAA supplementation. A decrease in plasma concentration of serine in pigs was also detected after Leu supplementation ${ }^{(47,51)}$. As phenylalanine, serine and cysteine can be utilised by portal-drained viscera and liver, the decreases in arterial levels are likely due to the increased utilisation in these two tissues. However, the reason and significance of this increase in catabolism following BCAA supplementation remain to be further investigated.

\section{Modulation of muscle net amino acid fluxes by branched- chain amino acids as the direct signaling molecules}

The feeding-induced stimulation of muscle protein synthesis in pigs is independently regulated by the increase of insulin and $\mathrm{AA}^{(54)}$. Our previous study has shown that the level of plasma insulin is not affected by BCAA supplementation ${ }^{(55)}$, which is consistent with results of other studies obtained by the infusion of individual BCAA or mixed $\mathrm{EAA}^{(4,56)}$. Thus, it seems that the anabolic effect of BCAA is unlikely mediated by insulin. Apart from building blocks for protein synthesis, BCAA, especially Leu, also serve as nutrient signals to promote muscle protein synthesis by stimulating translation initiation in pigs $^{(49-51)}$. Our recent study showed that the increase in muscle mass of young pigs after supplementation of BCAA is associated with the activation of translation initiation factors, including mTOR and $\mathrm{S} 6 \mathrm{~K} 1^{(6)}$. These results indicate that the supplementation of BCAA increases their intramuscular concentrations, and thus stimulates translation initiation, leading to an elevation of muscle net AA fluxes.

\section{Modulation of muscle net amino acid fluxes by catabolism} of branched-chain amino acids

BCAA not only serve as the substrate for protein synthesis but also are catabolised extensively in skeletal muscle. As described above, BCAA catabolism in muscle promotes the synthesis of glutamine, glutamate and aspartate, which are extensively catabolised by pig small intestine, and thus may reduce protein mobilisation and increase protein synthesis. Correspondingly, in this study, the metabolomic profiling of femoral vein of the control and BCAA-supplemented pigs revealed a BCAA-related metabolite signature that was suggestive of increased catabolism of BCAA (Table 4), which was associated with the increased muscle net AA fluxes. Two major classes of metabolites, BCKA and lipid metabolism-related products, were identified to be different between the control and BCAAsupplemented pigs. Similarly, the alteration of lipid metabolism induced by BCAA supplementation was previously reported for rats fed high-fat diet ${ }^{(57)}$. Interestingly, the ability of Leu to act as a nutrient signal to stimulate muscle protein synthesis is specific for Leu and/or its transamination metabolite KIC. KIC is potentially used to promote muscle protein synthesis through stimulating translation initiation ${ }^{(5,18)}$. Increased muscle net KIC and KMV production was observed after BCAA supplementation in the present study, which was strongly and positively correlated with muscle net AA fluxes (Table 5). Furthermore, infusion of another Leu metabolite $\beta$-hydroxy- $\beta$-methylbutyrate to piglets resulted in the activation of translation initiation and an increase in muscle protein synthesis ${ }^{(58)}$. These results indicate that the elevation of BCAA catabolism may contribute to the increase of net AA fluxes in muscle after BCAA supplementation. Further studies are needed to determine the direct roles of these metabolites of BCAA in regulating muscle net AA fluxes and protein synthesis.

In summary, supplementation of BCAA to reduced-protein diet increases the substrate concentrations of BCAA in both arterial plasma and muscle, and enhances the intramuscular catabolism of BCAA, which promotes the synthesis of BCKA and several NEAA, particularly glutamine. The increased substrate concentrations and catabolism of BCAA may increase muscle net AA fluxes, and thereby lead to the elevation of muscle protein deposition in young pigs. These results provide a direct biochemical explanation for the anabolic effect of BCAA on muscle protein metabolism. Our findings also indicate that rather than to be a nutritional loss, the catabolism of BCAA in muscle is of enormous biological importance. Furthermore, our hindlimb flux model combined with metabolite profiling identified some BCAA-related metabolites (such as BCKA and EPA, etc.), which may potentially and partially mediate BCAA dependent-increase of muscle net AA flux and growth.

\section{Acknowledgements}

The authors are grateful to Associate Professor Zuoxiong Liu for English editing.

The work was jointly supported by the National Basic Research Program of China (973 Program) (no. 2013CB127305), and the Key Technology Research and Development Program of Hubei Province (nos 2014ABB014 and 2014ABC012).

The authors' contributions are as follows: J. Peng, L. Z., H. W. and S. Z. designed the research; L. Z., F. Z., S. Z., P. H., Q. X. and J. Pang conducted the research; L. Z., F. Z. and P. H. analysed the data; L. Z., H. W. and J. Peng wrote the manuscript. J. Peng had primary responsibility for the final content. All authors read and approved the final manuscript.

None of the authors has any conflicts of interest to declare

\section{References}

1. Shavlakadze T \& Grounds M (2006) Of bears, frogs, meat, mice and men: complexity of factors affecting skeletal muscle mass and fat. Bioessays 28, 994-1009.

2. Louard RJ, Barrett EJ \& Gelfand RA (1990) Effect of infused branched-chain amino acids on muscle and whole-body amino acid metabolism in man. Clin Sci (Lond) 79, 457-466.

3. Nagasawa T, Kido T, Yoshizawa F, et al. (2002) Rapid suppression of protein degradation in skeletal muscle after oral feeding of leucine in rats. J Nutr Biochem 13, 121-127.

4. Escobar J, Frank JW, Suryawan A, et al. (2006) Regulation of cardiac and skeletal muscle protein synthesis by individual branched-chain amino acids in neonatal pigs. Am J Physiol Endocrinol Metab 290, E612-E621. 
5. Columbus DA, Fiorotto ML \& Davis TA (2015) Leucine is a major regulator of muscle protein synthesis in neonates. Amino Acids 47, 259-270.

6. Zheng L, Wei H, Cheng C, et al. (2016) Supplementation of branched-chain amino acids to a reduced-protein diet improves growth performance in piglets: involvement of increased feed intake and direct muscle growthpromoting effect. Br J Nutr 115, 2236-2245.

7. Columbus DA, Steinhoff-Wagner J, Suryawan A, et al. (2015) Impact of prolonged leucine supplementation on protein synthesis and lean growth in neonatal pigs. Am J Physiol Endocrinol Metab 309, E601-E610.

8. Manjarín R, Columbus DA, Suryawan A, et al. (2016) Leucine supplementation of a chronically restricted protein and energy diet enhances mTOR pathway activation but not muscle protein synthesis in neonatal pigs. Amino Acids 48, 257-267.

9. Jourdan M, Deutz NE, Cynober L, et al. (2013) Consequences of age-related splanchnic sequestration of leucine on interorgan glutamine metabolism in old rats. J Appl Physiol (1985) 115, 229-234.

10. Deutz NEP, Bruins MJ \& Soeters PB (1998) Infusion of soy and casein protein meals affects interorgan amino acid metabolism and urea kinetics differently in pigs. J Nutr 128, 2435-2445.

11. Thivierge MC, Bush JA, Suryawan A, et al. (2008) Positive net movements of amino acids in the hindlimb after overnight food deprivation contribute to sustaining the elevated anabolism of neonatal pigs. J Appl Physiol(1985) 105, 1959-1966.

12. Shimomura Y, Yamamoto Y, Bajotto G, et al. (2006) Nutraceutical effects of branched-chain amino acids on skeletal muscle. J Nutr 136, 529S-532S.

13. Harper AE, Miller RH \& Block KP (1984) Branched-chain amino acid metabolism. Annu Rev Nutr 4, 409-454.

14. Holeček M (2002) Relation between glutamine, branchedchain amino acids, and protein metabolism. Nutrition 18, 130-133.

15. Li P, Knabe DA, Kim SW, et al. (2009) Lactating porcine mammary tissue catabolizes branched-chain amino acids for glutamine and aspartate synthesis. J Nutr 139, 1502-1509.

16. Stoll B \& Burrin D (2006) Measuring splanchnic amino acid metabolism in vivo using stable isotopic tracers. J Anim Sci 84, E60-E72.

17. Wu G, Bazer FW, Burghardt RC, et al. (2010) Functional amino acids in swine nutrition and production. In Dynamics in Animal Nutrition, pp. 69-98 [J Doppenberg and P van der Aar, editors]. The Netherlands: Wageningen Academic Publishers.

18. Escobar J, Frank JW, Suryawan A, et al. (2010) Leucine and $\alpha$-ketoisocaproic acid, but not norleucine, stimulate skeletal muscle protein synthesis in neonatal pigs. J Nutr 140, 1418-1424.

19. Nakashima K, Yakabe Y, Ishida A, et al. (2007) Suppression of myofibrillar proteolysis in chick skeletal muscles by $\alpha$-ketoisocaproate. Amino Acids 33, 499-503.

20. Jones DP, Park Y \& Ziegler TR (2012) Nutritional metabolomics: progress in addressing complexity in diet and health. Annu Rev Nutr 32, 183.

21. Paris LP, Johnson CH, Aguilar E, et al. (2016) Global metabolomics reveals metabolic dysregulation in ischemic retinopathy. Metabolomics 12, 1-10.

22. Brennan L (2013) Metabolomics in nutrition research: current status and perspectives. Biochem Soc Trans 41, 670-673.

23. National Research Council (NRC) (2012) Nutrient Requirements of Swine, 11th rev. ed. Washington, DC: The National Academies Press

24. National Research Council (NRC) (1998) Nutrient Requirements of Swine, 10th rev. ed. Washington, DC: The National Academies Press.
25. Fang ZF, Luo J, Qi ZL, et al. (2009) Effects of 2-hydroxy-4methylthiobutyrate on portal plasma flow and net portal appearance of amino acids in piglets. Amino Acids 36, 501-509.

26. Stoll B, Henry J, Reeds PJ, et al. (1998) Catabolism dominates the first-pass intestinal metabolism of dietary essential amino acids in milk protein-fed piglets. J Nutr 128, 606-614.

27. Ettrup KS, Glud AN, Orlowski D, et al. (2011) Basic surgical techniques in the Göttingen minipig: intubation, bladder catheterization, femoral vessel catheterization, and transcardial perfusion. J Vis Exp 52, 2652.

28. Riedijk MA, Stoll B, Chacko S, et al. (2007) Methionine transmethylation and transsulfuration in the piglet gastrointestinal tract. Proc Natl Acad Sci U S A 104, 3408-3413.

29. Yin B, Li T, Li Z, et al. (2015) Determination of melatonin and its metabolites in biological fluids and eggs using highperformance liquid chromatography with fluorescence and quadrupole-orbitrap high-resolution mass spectrometry. Food Anal Method 9, 1142-1149.

30. Olson KC, Chen G \& Lynch CJ (2013) Quantification of branchedchain keto acids in tissue by ultra fast liquid chromatographymass spectrometry. Anal Biochem 439, 116-122.

31. Lin G, Liu C, Feng C, et al. (2012) Metabolomic analysis reveals differences in umbilical vein plasma metabolites between normal and growth-restricted fetal pigs during late gestation. J Nutr 142, 990-998.

32. Ten have GAM, Bost MCF, Suyk-Wierts JCAW, et al. (1996) Simultaneous measurement of metabolic flux in portallydrained viscera, liver, spleen, kidney and hindquarter in the conscious pig. Lab Anim 30, 347-358.

33. Nason GJ, Barry BD, Obinwa O, et al. (2014) Early rise in C-reactive protein is a marker for infective complications in laparoscopic colorectal surgery. Surg Laparosc Endosc Percutan Tech 24, 57-61.

34. Davis TA, Burrin DG, Fiorotto ML, et al. (1996) Protein synthesis in skeletal muscle and jejunum is more responsive to feeding in 7-than in 26-day-old pigs. Am J Physiol 270, E802-E809.

35. Davis TA, Fiorotto ML, Burrin DG, et al. (2002) Stimulation of protein synthesis by both insulin and amino acids is unique to skeletal muscle in neonatal pigs. Am J Physiol Endocrinol Metab 282, E880-E890.

36. Wu G (2009) Amino acids: metabolism, functions, and nutrition. Amino Acids 37, 1-17.

37. Pond WG \& Mersmann HJ (2001) Biology of the Domestic Pig. Ithaca, New York: Cornell University Press.

38. Mittendorfer B, Volpi E \& Wolfe R (2001) Whole body and skeletal muscle glutamine metabolism in healthy subjects. $\mathrm{Am}$ J Physiol Endocrinol Metab 280, E323-E333.

39. Wu G \& Thompson JR (1990) The effect of glutamine on protein turnover in chick skeletal muscle in vitro. Biochem $J$ 265, 593-598.

40. Lecker SH, Jagoe RT, Gilbert A, et al. (2004) Multiple types of skeletal muscle atrophy involve a common program of changes in gene expression. FASEB J 18, 39-51.

41. Karinch AM, Pan M, Lin C-M, et al. (2001) Glutamine metabolism in sepsis and infection. J Nutr 131, 2535S-2538S.

42. Goldberg AL \& Odessey R (1972) Oxidation of amino acids by diaphragms from fed and fasted rats. Am J Physiol 223, 1384-1391.

43. Rennie MJ \& Tipton KD (2000) Protein and amino acid metabolism during and after exercise and the effects of nutrition. Annu Rev Nutr 20, 457-483.

44. Wu G \& Thompson JR (1989) Is methionine transaminated in skeletal muscle? Biochem J 257, 281.

45. Wu G \& Thompson JR (1989) Methionine transamination and glutamine transaminases in skeletal muscle. Biochem $J$ 262, 690 . 
46. Lordelo M, Gaspar A, Le Bellego L, et al. (2008) Isoleucine and valine supplementation of a low-protein corn-wheat-soybean meal-based diet for piglets: growth performance and nitrogen balance. J Anim Sci 86, 2936-2941.

47. Soumeh E, van Milgen J, Sloth N, et al. (2015) The optimum ratio of standardized ileal digestible leucine to lysine for 8 to $12 \mathrm{~kg}$ female pigs. J Anim Sci 93, 2218-2224.

48. Wu G, Bazer FW, Dai Z, et al. (2014) Amino acid nutrition in animals: protein synthesis and beyond. Annu Rev Anim Biosci 2, 387-417.

49. Murgas Torrazza R, Suryawan A, Gazzaneo MC, et al. (2010) Leucine supplementation of a low-protein meal increases skeletal muscle and visceral tissue protein synthesis in neonatal pigs by stimulating mTOR-dependent translation initiation. J Nutr 140, 2145-2152.

50. Suryawan A, Torrazza RM, Gazzaneo MC, et al. (2012) Enteral leucine supplementation increases protein synthesis in skeletal and cardiac muscles and visceral tissues of neonatal pigs through mTORC1-dependent pathways. Pediatr Res 71, 324-331.

51. Yin Y, Yao K, Liu Z, et al. (2010) Supplementing L-leucine to a low-protein diet increases tissue protein synthesis in weanling pigs. Amino Acids 39, 1477-1486.

52. Taylor P, Rennie M \& Low S (1999) Biomembrane transport and interorgan nutrient flows: the amino acids. In Biomembrane
Transport, pp. 295-325 [LJ Van Winkle, editor]. New York: Academic.

53. Bohé J, Low A, Wolfe RR, et al. (2003) Human muscle protein synthesis is modulated by extracellular, not intramuscular amino acid availability: a dose-response study. J Physiol 552, 315-324.

54. O'Connor PM, Bush JA, Suryawan A, et al. (2003) Insulin and amino acids independently stimulate skeletal muscle protein synthesis in neonatal pigs. Am J Physiol Endocrinol Metab 284, E110-E119.

55. Zheng L, Wei H, He P, et al. (2016) Effects of supplementation of branched-chain amino acids to reduced-protein diet on skeletal muscle protein synthesis and degradation in the fed and fasted states in a piglet model. Nutrients $\mathbf{9}, 17$.

56. Volpi E, Kobayashi H, Sheffield-Moore M, et al. (2003) Essential amino acids are primarily responsible for the amino acid stimulation of muscle protein anabolism in healthy elderly adults. Am J Clin Nutr 78, 250-258.

57. Newgard CB, An J, Bain JR, et al. (2009) A branched-chain amino acid-related metabolic signature that differentiates obese and lean humans and contributes to insulin resistance. Cell Metab 9, 311-326.

58. Wheatley SM, El-Kadi SW, Suryawan A, et al. (2014) Protein synthesis in skeletal muscle of neonatal pigs is enhanced by administration of $\beta$-hydroxy- $\beta$-methylbutyrate. Am $J$ Physiol Endocrinol Metab 306, E91-E99. 